\title{
Structural and Stability Investigation of the Anticancer Drug Cyclophosphamide via Quantum Chemical Calculations: A Nanotube Drug Delivery
}

\author{
Z. FELEGARI* \\ Department Of Chemistry, Science and Research Branch, Islamic Azad University, Tehran, Iran. \\ *Corresponding author E-mail: z.felegari2014@gmail.com
}

http://dx.doi.org/10.13005/ojc/300447

(Received: September 12, 2014; Accepted: October 04, 2014)

\section{ABSTRACT}

\begin{abstract}
Cyclophosphamide is a medicine used to interfere with the growth and spread of tumor cells and treat cancers and autoimmune disorders. This work reports the study of anticancer drugs with density functional theory (DFT) and electronic structures.Its structure was optimized with B3LYP/6-311G* level in the gas phase and different solvents (SCRF calculation). NBO analysis,NMR parameter,thermodynamic properties, HOMO and LUMO,HOMO-LUMO band gap, and the electronic chemical potential $(\mu)$ were calculated. The results indicated that the Cyclophosphamide in water solvent is more stable than the gas phase orother solvents.
\end{abstract}

Key words: Cyclophosphamide, NBO,NMR parameter,HOMO-LUMO gap,DFT.

\section{INTRODUCTION}

Cyclophosphamide(Procytox or Cytoxan) is a drug used in the treatment of cancer, andis in a class of drugs known as alkylating agents. Cyclophosphamide $\left(\mathrm{C}_{7} \mathrm{H}_{15} \mathrm{Cl}_{2} \mathrm{~N}_{2} \mathrm{O}_{2} \mathrm{P}\right)$ is also used to treat bronchogenic carcinoma, small cell lung carcinoma, and other types of cancer ${ }^{1-3}$.

It is obvious, drug delivery technology modifies drug release profile, absorption, distribution and elimination for the benefit of improving product efficacy and safety, as well as patient convenience and compliance ${ }^{4-7}$.

For this reason many protein and peptide drugs have to be delivered by injection or a nanoneedlearray.Today efforts in the area of drug delivery include the development of targeted delivery in which the drug is only active in the target area of the body ${ }^{8-11}$.

Cyclophosphamide is biotransformed principally into the liver to active alkylating 
metabolites by a mixed functionof microsomal oxidase system. These metabolites interfere with the growth of susceptible rapidly proliferatingmalignant cells. The mechanism of action is thought to involve the cross-linking of tumor cell DNAs. Cyclophosphamide is well absorbed after oral administration, with a bioavailability of greater than $75 \%$. Theunchanged drug has an elimination half-life of 3-12 hours. It is eliminated primarily in the form of metabolites,but $5-25 \%$ of the dose is excreted in urine in its original form. Several cytotoxic and noncytotoxicmetabolites have been detectedin urine and plasma. Concentrations of metabolites was maximized inplasma in 2-3 hours after an intravenous dose. Plasma protein binding of unchanged drug is low, but somemetabolites are bound to an extent of greater than $60 \%$. It has not been demonstrated that any single metaboliteis responsible for either the therapeutic or toxic effects of cyclophosphamide. Although elevated levels of metabolitesof cyclophosphamide have been observed in patients with renal failure, increased clinical toxicity in suchpatients has not been demonstrated ${ }^{12-17}$.

An alkylating agent adds an alkyl group $\left(\mathrm{C}_{\mathrm{n}} \mathrm{H}_{2 \mathrm{n}+1}\right)$ to DNAmoleculesthat linksit with this method, while DNA replicationisinhibited.DNA is one of the most important biologicalmolecules targeted by many smaller molecules (proteinsre presenting extremely important targets as well). Many of scientists have focused on biological applications of inorganic systems so nano sensors based on biology in biomedical devices and bioreactors have considerable applied in the last years $^{18-20}$.

Also,during the past decades, molecules binding with DNAAhave been seriously taken into account ${ }^{21,22}$. A lot ofinvestigations of the interaction of drug molecules withDNA have been studied ${ }^{23-27}$.

The integration of biological processes and synthesize molecules with fabricated structures presented also both electronic control and bioelectronically driven nano-assembly ${ }^{28-30}$.

As a specific example, hollow cylinders that made of many sheets of carbon atoms to mean carbon nanotubes have recommended for use in nervous systems as prosthetic implants, and obtaining this goal requires the incorporation of fully functioning nano-electronic and biological systems $^{31,32}$.

In this work letter, we report our study on the stability of the anticancer drug Cyclophosphamide in the gas phase and different solvents. We found that the Cyclophosphamide behave differently in the gas and solvent phase.

\section{Computational method}

Wemodeled the structure of Cyclophosphamide with Gauss view $5.0^{33}$, and then optimized it in thegas phase and different solvents, such as Water, DMSO, Ethanol, and Methanol.

All calculations were carried out with the Gaussian 09program[34]. The calculations of systems containing $\mathrm{C}, \mathrm{H}, \mathrm{N}, \mathrm{P}, \mathrm{O}$ and $\mathrm{Cl}$ are explained by the standard6-311G (d) basis set function of the Density Functional Theory (DFT) ${ }^{35,36}$.

Afteroptimization, we calculated the NMR parameters and NBO. The population analysis has been performed by the natural bond orbital method at B3LYP/6-311G (d) level of theory using natural bondorbital (NBO) $)^{37-43}$.

NBO analysis used the B3LYP method and $6-311 G^{*}$ basis set, and the output is obtained for molecule. Finally, the highest occupied molecular orbital (HOMO), lowest unoccupied molecular orbital (LUMO), energy gaps, and thermodynamic properties have been discussed $d^{40-43}$

We calculated the NMR parameters at the levels of B3LYP/6-311G* theory ${ }^{44,45}$, and theoretically explored the effects of solvent (water, DMSO, methanol, ethanol) on the structure of Cyclophosphamide. All the relative energy values and NMR shielding parameters were calculated by assuming that thegauge includes the atomic orbital (GIAO) method. TheGauge Including Atomic Orbital (GIAO) $)^{46-48}$ approach was used ${ }^{49,50}$. The abinitio GIAO calculations of NMR chemical shielding tensors were performed using the DFT method ${ }^{51}$. The chemical shielding tensors were calculated by the GAUSSIAN 09 program ${ }^{52}$. 


\section{RESULTSAND DISCUSSION}

In our study, we performed quantum calculations on the structure of Cyclophosphamide, which isan important anticancer drug. Therefore, HF and DFT methods, with 6-311G*basis set, were employed toinvestigate the structures, optimization, and energy minimization of Cyclophosphamide (Fig.1) in thegasphase and different solvents (Water, DMSO, Ethanol and Methanol) that have been summarized in Tables $1 \mathrm{a}$ and $1 \mathrm{~b}$. Wetake this medicationto the Quantum computation phase solvents,such as water, DMSO, ethanol and methanol were used in the following ways to deduce the effect of solvents on the drug.Also, we effectively investigated the solvent on this drug, and optimized it at the B3LYP levels of theory, with 6$311 \mathrm{G}^{*}$ basis set being summarized in Table $1 \mathrm{~b}$.According to the values listed in Table $1 \mathrm{~b}$, it indicates that the solvent effect the bond lengths, so $\left(\mathrm{C}_{2}-\mathrm{C}_{3}\right),\left(\mathrm{C}_{3}-\mathrm{H}_{8}\right),\left(\mathrm{P}_{12}-\mathrm{N}_{13}\right)$ and $\left(\mathrm{P}_{12}-\mathrm{N}_{25}\right)$ in water is shorter than the gas phase and other solvents.Also, $\left(\mathrm{P}_{12}-\mathrm{O}_{14}\right)$ in water is longer than the gas phase andother solvents, which proves that electron-donor atoms decreases bond lengths, whiletheelectron-pull atoms increases it.

The highest occupied molecular orbital (HOMO), the lowest unoccupied molecular orbital (LUMO), and the energy gapwas calculated by B3LYP/6-311G*method, and are provided in Table 2. The HOMO represents the ability to donate an electron,while LUMO acts as an electron acceptor, representing the ability to obtain an electron. The electron transition absorption corresponds to the transition from the ground to the first excited state, and is mainly described by electron excitation from HOMO to LUMO.

The energy gap between HOMO and LUMO is a critical parameter in determining molecular electrical transport properties ${ }^{53,54}$.The

Table 1(a): Optimizes energy for each phase

\begin{tabular}{lccccc}
\hline 6-311G* & Gas & H2O & E(Kcal/mol) & & \\
& & & DMSO & Ethanol & Methanol \\
\hline HF & -4701316.8259 & -4701358.2685 & -4701357.4816 & -4701355.6456 & -4701356.4325 \\
B3LYP & -4715410.4609 & -4715456.8871 & -4715456.1001 & -4715454.5264 & -4715455.3133 \\
\hline
\end{tabular}

Table 1(b): Bond Lengths $\left(A^{0}\right)$ for Cyclophosphamide in Gas phase and different solvent

\begin{tabular}{lccccc}
\hline Atom & Gas & Water & DMSO & Ethanol & Methanol \\
\hline C2-C3 & 1.52413 & 1.52067 & 1.52077 & 1.52085 & 1.52078 \\
C3-H8 & 1.09499 & 1.09421 & 1.09423 & 1.09424 & 1.09423 \\
P12-O14 & 1.48259 & 1.49236 & 1.49220 & 1.49179 & 1.49197 \\
P12-N13 & 1.69209 & 1.67533 & 1.67558 & 1.67628 & 1.67596 \\
P12-N25 & 1.66929 & 1.66929 & 1.66935 & 1.66937 & 1.66934 \\
\hline
\end{tabular}

Table 2: Obtained some Parameter by B3LYP/6-311G* Level

\begin{tabular}{lccccc}
\hline Parameter & Gas & Water & DMSO & Ethanol & Methanol \\
\hline EHOMO $(\mathrm{eV})$ & -6.9277 & -6.7201 & -6.9249 & -6.9129 & -6.9128 \\
ELUMO $(\mathrm{eV})$ & 0.1428 & -0.0144 & 0.1331 & 0.1853 & 0.1850 \\
Energy gap $(\mathrm{eV})$ & 7.0705 & 6.7057 & 7.058 & 7.0973 & 7.0978 \\
$\mu(\mathrm{eV})$ & -3.3815 & -3.4095 & -3.4036 & -3.0197 & -3.4024 \\
\hline
\end{tabular}


HOMO and LUMO of Cyclophosphamide are represented in Table 2 and Fig.2. The energy gap and electron potential in water solvent arelarger than other solvents.A large gap implies high stability, while a small gap implies low stability. The high stability in turn indicates low chemical reactivity, and a small gap indicates high chemical reactivity. Therefore, the results confirm the stability of Cyclophoshamide in water.

The isotropic chemical shielding $\left(\sigma_{i s o}\right)$ and anisotropy shielding $(\Delta \sigma)$ for $\mathrm{O}_{14}, \mathrm{Cl}_{28}$, and $\mathrm{Cl}_{29}$ of Cyclophosphamide calculated in the gas phase and different solvents (Fig.1) are summarized in Table 3 , as thehighest and the lowest density ofcharges is concentratedonthese atoms (Fig.3,4). olvent, $183.368 \mathrm{ppm}$, is higher than other solvents.

The blue regions show the most electron deficient regions, while the red color areas show the most electron accumulation regions. Therefore, the $\mathrm{O}_{14}, \mathrm{Cl}_{28}$, and $\mathrm{Cl}_{29}$ is regarded asimportant. The chemical shift value of $\mathrm{O}_{14}$ in waters.

We calculated the thermodynamic functions, such as constant volume molar heat capacity $\left(C_{v}\right)$, enthalpy $(H)$, Gibbs free energy $(G)$, total energy (E), and entropy (S) for Cyclophosphamide in the gas phase and different solvents obtained from the theoretical method by B3LYP/6-311G* andits respectivevalues listed in Table4.All of the thermodynamic data supply helpful information for a study on the Cyclophosphamide. They can be used to compute other thermodynamic energies according to the relationships of thermodynamic functions ${ }^{55}$.

We compared the gas phase and solvent effects on thethermodynamic parameter of Cyclophosphamide. Table 8 showed that the total

Table 3: NMR parameter's value $\sigma_{\text {iso }}(\mathrm{ppm})$ and $\Delta \sigma$ (ppm) of O14, Cl28, Cl29Of Cyclophosphamide in Gas phase and different solvent at the level of B3LYP/ 6-311G* basis set at the DFT theory

\begin{tabular}{lccccc}
\hline B3LYP/6-311G* & $\begin{array}{c}\text { Isotropic } \\
\text { (ólSO) }\end{array}$ & $\begin{array}{c}\text { Anisotropy } \\
(\boldsymbol{\Delta} \boldsymbol{\sigma})\end{array}$ & $\begin{array}{c}\text { B3LYPI } \\
\mathbf{6 - 3 1 1 G *}\end{array}$ & $\begin{array}{c}\text { Isotropic } \\
(\boldsymbol{\sigma} \text { ISO })\end{array}$ & $\begin{array}{c}\text { Anisotropy } \\
(\boldsymbol{\Delta} \boldsymbol{\sigma})\end{array}$ \\
\hline $\mathrm{O}_{14}$ (Gas) & 175.6586 & 103.2645 & $\mathrm{Cl}_{28}$ (DMSO) & 864.0924 & 55.085 \\
$\mathrm{P}_{12}$ (Gas) & 291.2206 & 266.0028 & $\mathrm{Cl}_{29}$ (DMSO) & 868.8859 & 40.5847 \\
$\mathrm{Cl}_{28}$ (Gas) & 855.7205 & 396.3267 & $\mathrm{O}_{14}$ (Ethanol) & 183.1043 & 24.9665 \\
$\mathrm{Cl}_{29}$ (Gas) & 857.2639 & 397.8573 & $\mathrm{P}_{12}$ (Ethanol) & 287.5821 & 54.858 \\
$\mathrm{O}_{14}$ (Water) & 183.368 & 39.9917 & $\mathrm{Cl}_{28}$ (Ethanol) & 863.8796 & 260.1108 \\
$\mathrm{P}_{12}$ (Water) & 287.3822 & 26.4779 & $\mathrm{Cl}_{29}$ (Ethanol) & 868.4794 & 260.1108 \\
$\mathrm{Cl}_{28}$ (Water) & 864.1848 & 55.1154 & $\mathrm{O}_{14}$ (Methanol) & 183.1961 & 40.3907 \\
$\mathrm{Cl}_{29}$ (Water) & 869.0759 & 258.4659 & $\mathrm{P}_{12}$ (Methanol) & 287.5194 & 25.4539 \\
$\mathrm{O}_{14}$ (DMSO) & 183.2886 & 40.8805 & $\mathrm{Cl}_{28}$ (Methanol) & 863.9808 & 54.9611 \\
$\mathrm{P}_{12}$ (DMSO) & 287.4358 & 25.9317 & $\mathrm{Cl}_{29}$ (Methanol) & 868.6892 & 259.5927 \\
\hline
\end{tabular}

Table 4: The calculated thermodynamic parameters $\left(\mathrm{E}_{\text {total }} \mathrm{kcal} / \mathrm{Mol}, \mathrm{CV} \mathrm{kcal} / \mathrm{Mol}, \mathrm{S} \mathrm{kcal} / \mathrm{molK}, \mathrm{H}\right.$ $\mathrm{kcal} / \mathrm{Mol}, \mathrm{G} \mathrm{kcal} / \mathrm{Mol}$ and $\mathrm{E} \mathrm{kcal} / \mathrm{Mol}$ ) of Cyclophosphamide in gas phase and different solvent

\begin{tabular}{lccccc}
\hline Parameter & Gas & Water & DMSO & Ethanol & Methanol \\
\hline$\varepsilon$ & - & 78.39 & 47 & 24.55 & 32.63 \\
$\mathrm{E}_{\text {total }}$ & 157.328 & 158.154 & 158.157 & 158.163 & 158.160 \\
$\mathrm{C}_{\mathrm{v}}$ & 56.393 & 56.518 & 56.512 & 56.502 & 56.507 \\
$\mathrm{~S}$ & 124.291 & 130.669 & 130.586 & 130.466 & 130.534 \\
$\mathrm{H}$ & -1797.494975 & -1797.515549 & -1797.515266 & -1797.514664 & -1797.514966 \\
$\mathrm{G}$ & -1797.554030 & -1797.577634 & -1797.577312 & -1797.576652 & -1797.576987 \\
$\mathrm{E}$ & -1797.495920 & -1797.516493 & -1797.516210 & -1797.515608 & -1797.515910 \\
\hline
\end{tabular}


energy $\left(E_{\text {total }}\right)$, entropy $(S)$, and constant volume molar heat capacity $\left(C_{v}\right)$ values are positive, whileenergy $\left(E_{\text {total }}\right)$, enthalpy $(H)$ and $G$ Gibbs' free energy are negative values. These calculations were repeated in various solvents with different dielectric constants. The resultsshowed that the stability of Cyclophosphamide is reduced by the decreasing polarisability of the solvents. The highest stability is observed for water, with $\mu=78.39$, while the lowest is for Ethanol, with $\mu=24.55$.
The natural bond orbital analysis provides theaccurate possible natural Lewis structure. The resultsof the interaction is a loss of occupancy from theconcentration of electron NBO of the idealizedLewis structure in an empty non-Lewis orbital. Acareful examination of all possible interactions between "filled" (donor) Lewis-type NBOs and "empty" (acceptor) non-Lewis NBOs allows us toestimate their energetic importance viathe second-order perturbation theory. For each donor(i) and acceptor (j), the stabilization energy $E$

Table 5:Donor and acceptor NBO for Cyclophosphamide and the level ofB3LYP/ 6-311G*in different solvents

\begin{tabular}{|c|c|c|c|c|c|}
\hline $\begin{array}{l}\text { Donor } \\
\text { NBO (i) }\end{array}$ & $\begin{array}{l}\text { Acceptor } \\
\text { NBO (j) }\end{array}$ & $\begin{array}{l}\text { E2 } \\
\text { (kcal/Mol) }\end{array}$ & $\begin{array}{l}\text { Donor } \\
\text { NBO (i) }\end{array}$ & $\begin{array}{l}\text { Acceptor } \\
\text { NBO (j) }\end{array}$ & $\begin{array}{l}\text { E2 } \\
\text { (kcal/Mol) }\end{array}$ \\
\hline $\begin{array}{l}\text { (Gas) LP (1) } \mathrm{O}_{14} \\
\text { (Gas) LP (2) } \mathrm{O}_{14} \\
\text { (Water) LP (1) } \mathrm{O}_{14} \\
\text { (Water) LP (2) } \mathrm{O}_{14} \\
\text { (Water) LP (3) O } \mathrm{O}_{14} \\
\text { (DMSO) LP (1) O } \mathrm{O}_{14} \\
\text { (DMSO) LP (2) O O }\end{array}$ & $\begin{array}{l}\mathrm{BD}^{*}(1) \\
\mathrm{P}_{12}-\mathrm{N}_{13} \\
\mathrm{BD}^{*}(1) \\
\mathrm{P}_{12}-\mathrm{N}_{13} \\
\mathrm{BD}^{*}(1) \\
\mathrm{P}_{12}-\mathrm{N}_{13} \\
\mathrm{BD}^{*}(1) \\
\mathrm{P}_{12}-\mathrm{N}_{13} \\
\mathrm{BD}^{*}(1) \\
\mathrm{O}_{11}-\mathrm{P}_{12} \\
\mathrm{BD}^{*}(1) \\
\mathrm{P}_{12}-\mathrm{N}_{13} \\
\mathrm{BD}^{*}(1) \\
\mathrm{P}_{12}-\mathrm{N}_{13}\end{array}$ & $\begin{array}{l}19.84 \\
1.09 \\
19.98 \\
24.97\end{array}$ & $\begin{array}{l}(\mathrm{DMSO}) \\
\mathrm{LP}(3) \mathrm{O}_{14} \\
(\text { Ethanol) } \\
\text { LP (1) } \mathrm{O}_{14} \\
(\text { Ethanol) } \\
\text { LP (2) } \mathrm{O}_{14} \\
(\text { Ethanol) } \\
\text { LP (3) } \mathrm{O}_{14} \\
\text { (Methanol) } \\
\text { LP (1) } \mathrm{O}_{14} \\
\text { (Methanol) } \\
\text { LP (2) } \mathrm{O}_{14} \\
\text { (Methanol) } \\
\text { LP (3) } \mathrm{O}_{14}\end{array}$ & $\begin{array}{l}\mathrm{BD}^{*}(1) \\
\mathrm{O}_{11}-\mathrm{P}_{12} \\
\mathrm{BD}^{*}(1) \\
\mathrm{P}_{12}-\mathrm{N}_{13} \\
\mathrm{BD}^{*}(1) \\
\mathrm{P}_{12}-\mathrm{N}_{13} \\
\mathrm{BD}^{*}(1) \\
\mathrm{O}_{11}-\mathrm{P}_{12} \\
\mathrm{BD}^{*}(1) \\
\mathrm{P}_{12}-\mathrm{N}_{13} \\
\mathrm{BD}^{*}(1) \\
\mathrm{P}_{12}-\mathrm{N}_{13} \\
\mathrm{BD}^{*}(1) \\
\mathrm{O}_{11}-\mathrm{P}_{12}\end{array}$ & $\begin{array}{l}19.75 \\
25.00 \\
1.09\end{array}$ \\
\hline
\end{tabular}

E (2) means energy of hyperconjugative interactions.

Table 6: Energy (kcal/Mol) and hybrid for P12-O14 bonding Cyclophosphamide

\begin{tabular}{lllll}
\hline DFT/B3LYP/6-311G* & Bond & Hybrid & Coefficients & Energy \\
\hline Gas/P ${ }_{12}-\mathrm{N}_{13}$ & $\mathrm{BD}(1)$ & $\begin{array}{l}\mathrm{P}=\mathrm{SP} 3.04 \\
\mathrm{~N}=\text { Sp2.53 d } 0.019\end{array}$ & $\begin{array}{l}0.5202 \\
0.8540\end{array}$ & -0.70872 \\
Water/P12-N13 & $\mathrm{BD}(1)$ & $\mathrm{P}=\mathrm{SP} 2.94 \mathrm{~d}^{0.8}$ & 0.8495 & \\
& & $\mathrm{~N}=\mathrm{SP} 2.38$ & 0.5276 & -0.73132 \\
DMSO/P12-N13 & $\mathrm{BD}(1)$ & $\mathrm{P}=\mathrm{SP} 2.95$ & 0.5276 & -0.73104 \\
& & $\mathrm{~N}=\mathrm{SP} 2.38 \mathrm{~d}^{0.08}$ & 0.8495 & \\
Ethanol/P12-N13 & $\mathrm{BD}(1)$ & $\mathrm{P}=\mathrm{SP} 2.95$ & 0.5275 & -0.73034 \\
& & $\mathrm{~N}=\mathrm{SP} 2.39 \mathrm{~d}^{0.08}$ & 0.8496 & \\
Methanol/P12-N13 & $\mathrm{BD}(1)$ & $\mathrm{P}=\mathrm{SP} 2.95$ & 0.527 & -0.73066 \\
& & $5 \mathrm{~N}=\mathrm{SP} 2.39 \mathrm{~d}^{0.08}$ & 0.8495 & \\
\hline
\end{tabular}




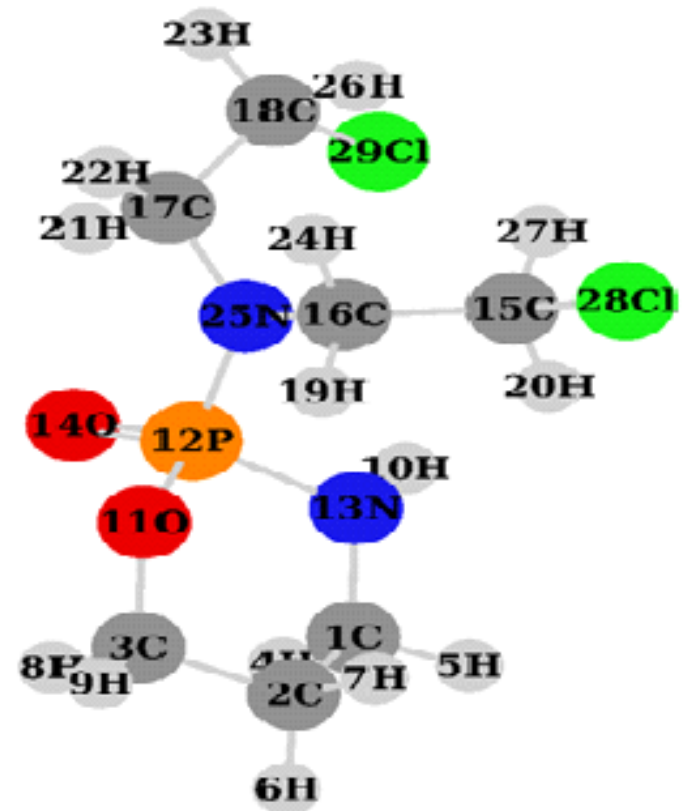

Fig.1: Structure of Cyclophosphamide
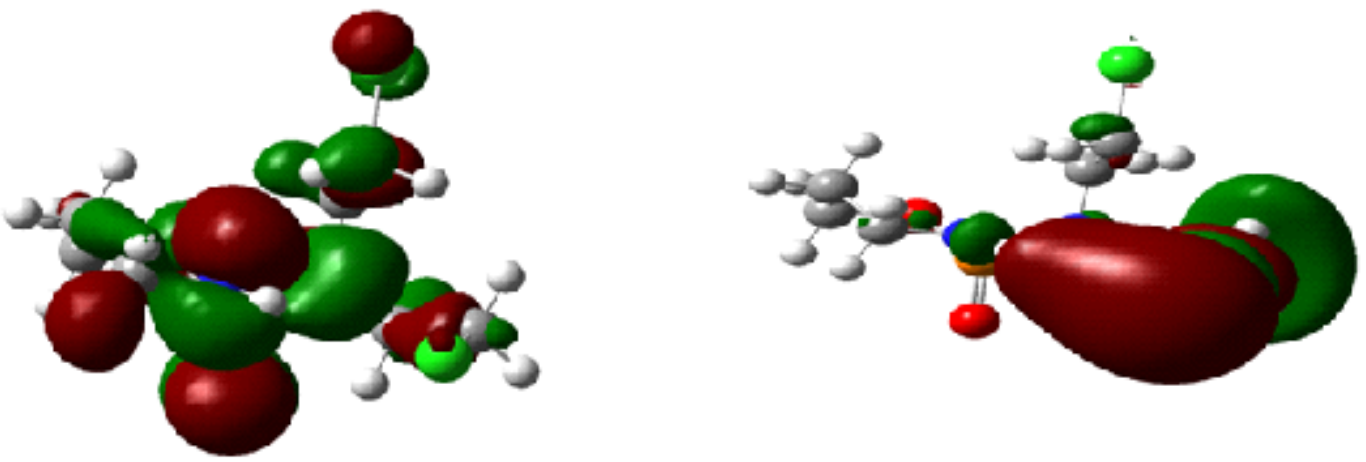

HOMO (Gas)LUMO (Gas)
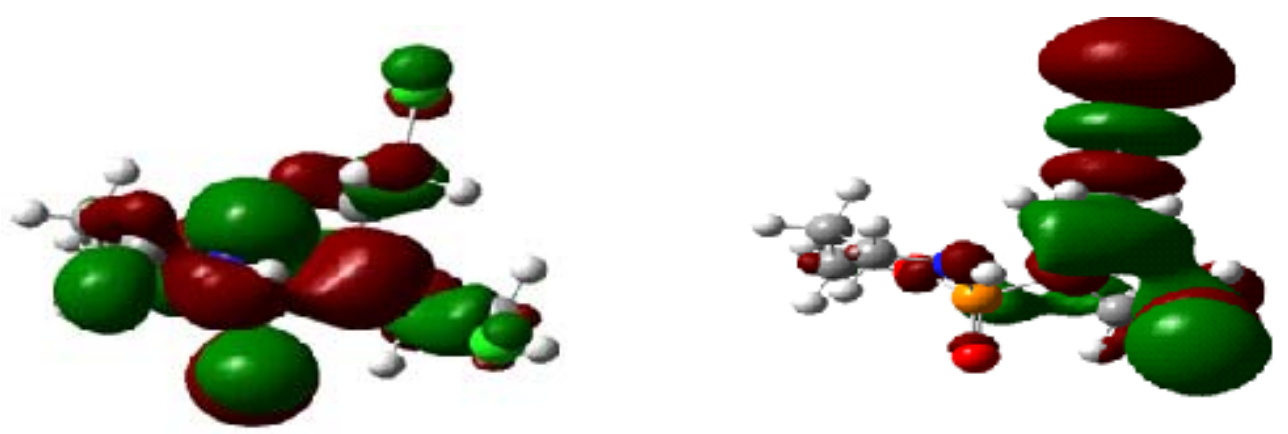


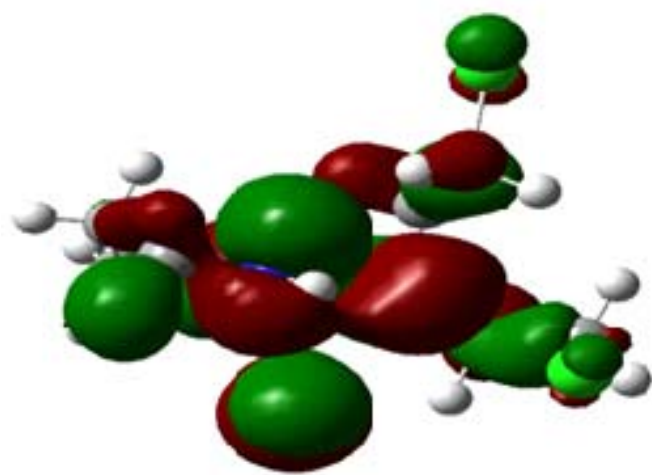

HOMO (DMSO)

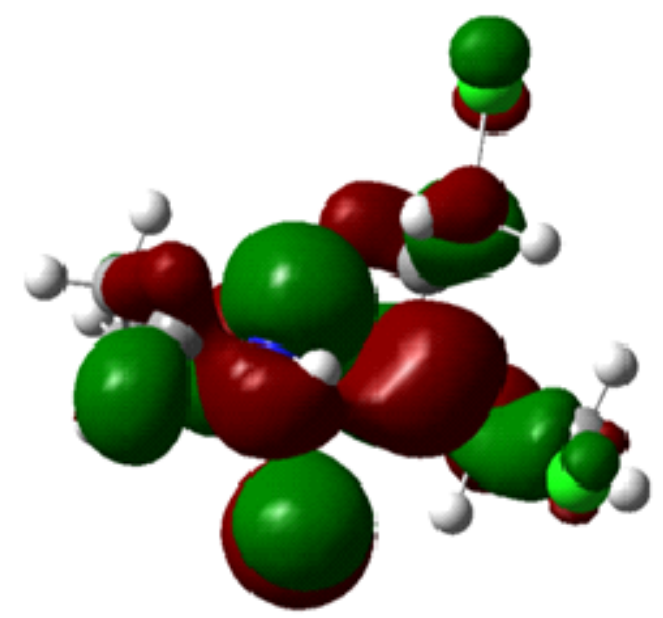

HOMO (Ethanol)

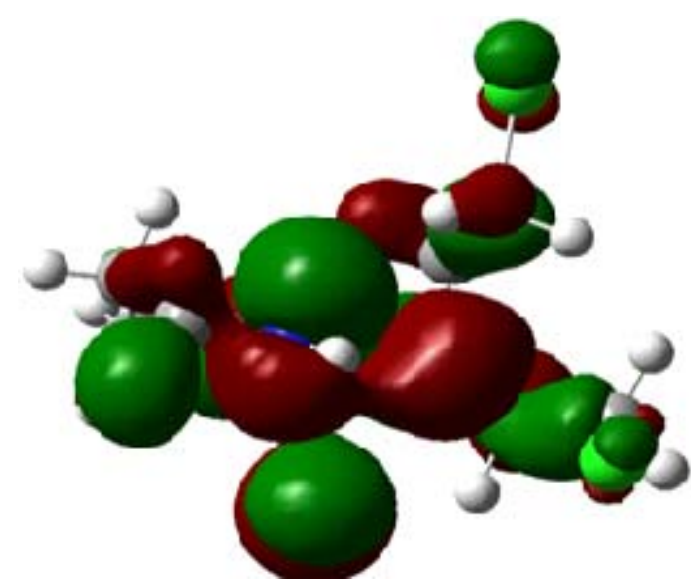

HOMO (Methanol)
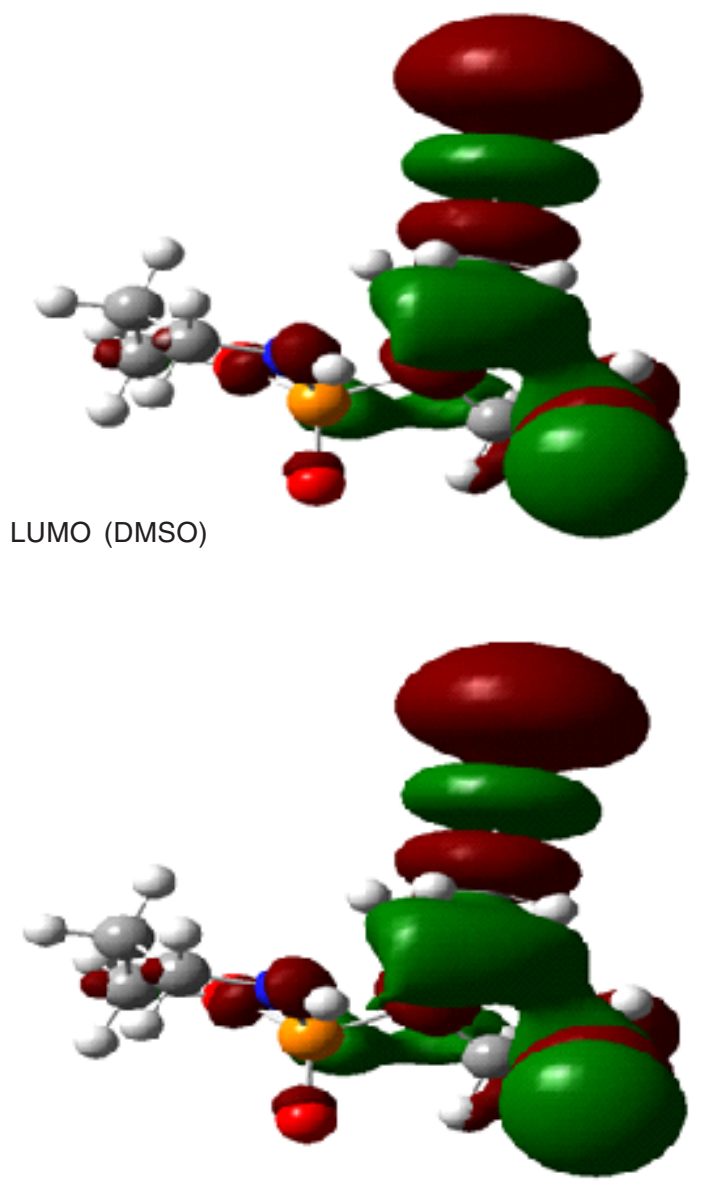

LUMO (Ethanol)

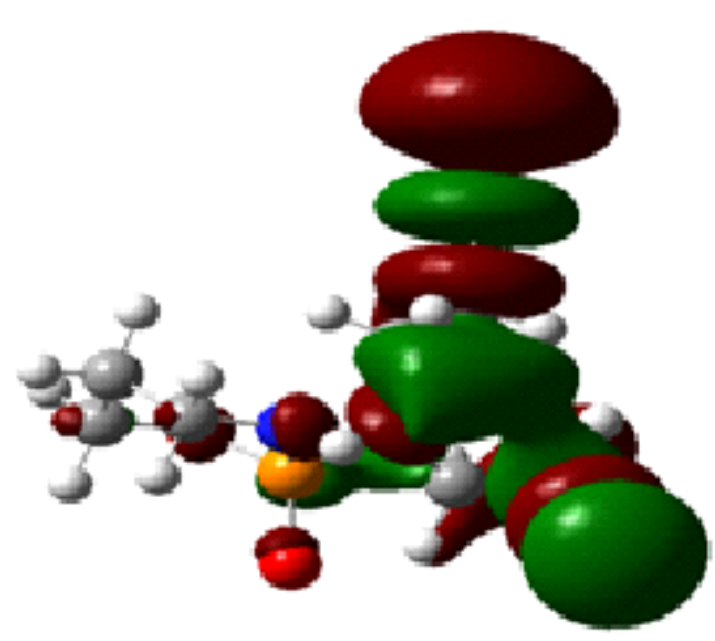

LUMO (Methanol)

Fig. 2: The HOMO and LUMO of Cyclophosphamide in Gas phase and different solvent 


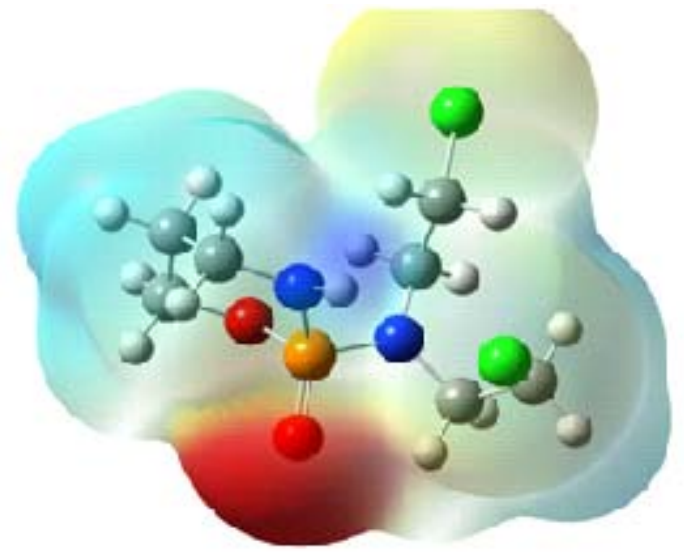

Fig .3: Electron density from Total SCF Density (isoval $=0.0004$ ) (2)is associated with the delocalization ${ }^{56}$. The strengths of these delocalization interactions, $\mathrm{E}^{(2)}$, are estimated by the second order perturbation theory. Some of the significant donor-acceptor interactions andtheir second order perturbation stabilization energies $E^{(2)}$ of Cyclophosphamide is givenin Table 4. This section shows some of the donor-acceptor interactions and their second order perturbation energies $E^{(2)}$ for Cyclophosphamide ${ }^{35}$.

The most important interaction between "filled" (donor) Lewis-type NBO and "empty" acceptor) non-Lewis is reported in Table 5, with the level of B3LYP/ 6-311G* basis set at the DFT theory. The electron density is transferred from lone pair<smiles>O=[P@]1(N(CCCl)CCCl)NCCCO1</smiles>

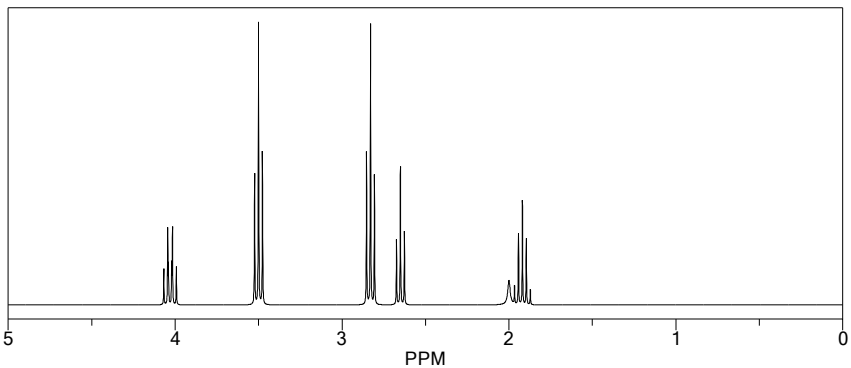<smiles>O=[P@@]1(N(CCCl)CCCl)C[CH]CCN1</smiles>
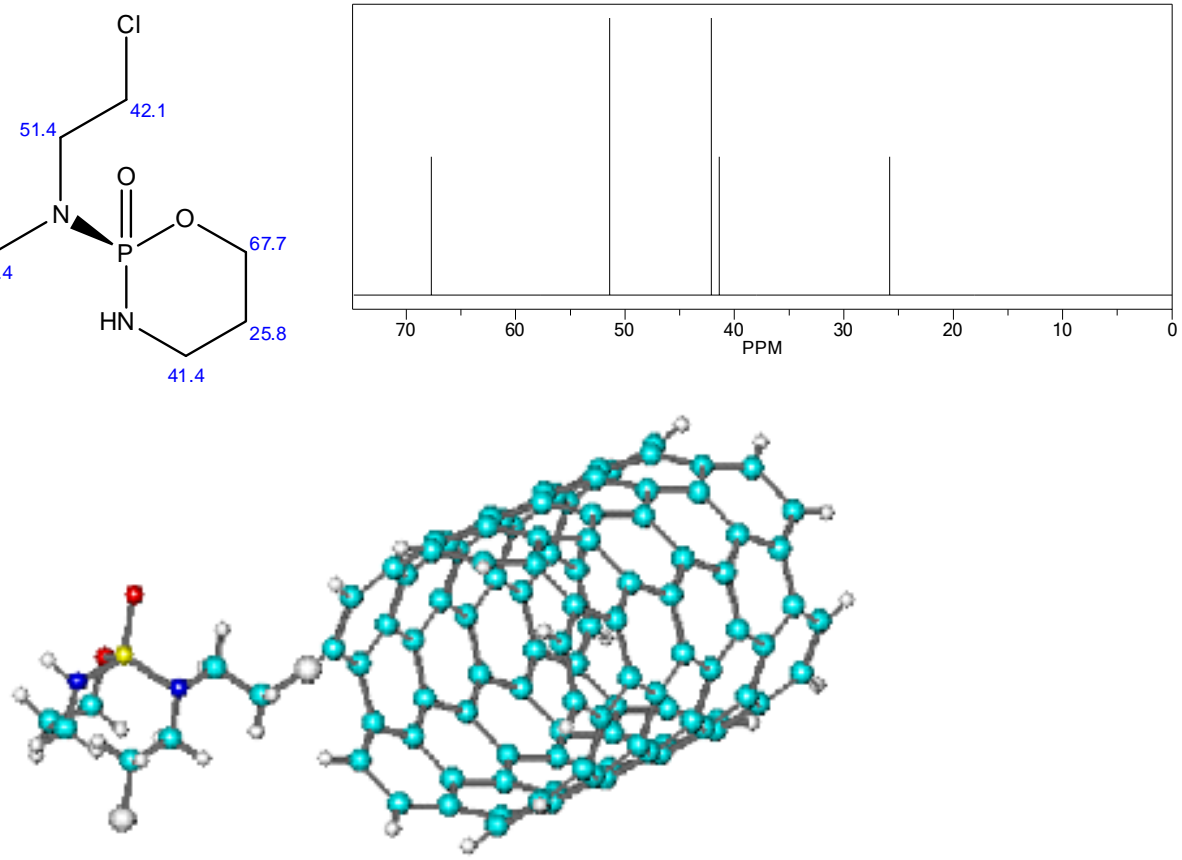

Fig. 4: Theoretical Results of (a)NMR ${ }^{1} \mathrm{H}$ and(b)NMR ${ }^{13} \mathrm{C}$ for optimized structure of Cyclophosphamide and(c) SWCNT $(5,5)$ armchair - Cyclophosphamide complex 
LP (2) $\mathrm{O}_{14}$ to anti-bonding $\sigma^{*}\left(\mathrm{P}_{12}-\mathrm{N}_{13}\right)$, where theinteraction is seen to provide a strong stabilization $19.59 \mathrm{KCal} / \mathrm{mol}$. This strong stabilization denotes larger delocalization ${ }^{48}$.Finally, we reported the Energy and Natural Hybrid Orbital (NHO) for $\mathrm{P}_{12}-\mathrm{N}_{13}$ bonding of Cyclophosphamidein Table 6. According to Table 6, in the $\mathrm{P}_{12}-\mathrm{N}_{13}$ bond, $\mathrm{BD}=0$. $5276 \mathrm{SP}^{2.94}$ d ${ }^{0.8}+0.8495 \mathrm{SP}^{2.35}$ was reported. Polarization coefficients of the $\mathrm{P}_{12}-\mathrm{N}_{13}$ bond are $P_{12}=0.5276$ and $N_{13}=0.8495$, thesize of these coefficients shows the importance of the hybrid $\mathrm{N}_{13}$ in the formation of the bond ${ }^{57,58}$.

\section{CONCLUSION}

In the present work, we studythe stability of Cyclophosphamide in the gas phase and different solvents. After optimization, the obtained data showedthat the Cyclophosphamide is stable in water. Also, theenergy gap of HOMO-LUMO confirms this stability. The $\sigma_{\text {iso }}$ value of $\mathrm{O}_{14}$ in water solvent is higher than the $\sigma_{\text {iso }}$ value in other solvents. This means that electron density around $\mathrm{O}_{14}$ in water solvent is higher compared to other solvents.According to NBO analysis $\mathrm{E}^{(2)}$ in water, it is higher than other solvents, and the thermodynamic parameters in water are higher, which again indicates the greater stability in water.Finally, our studies in the gas phase, and different solvents showed the Cyclophosphamide in water solvent is more stable than the gas phase and other solvents.

\section{REFERENCES}

1. Shanafelt TD, Lin T, Geyer SM, et al., Cancer 2007, 109(11): 2291-8.

2. Young SD, Whissell M, Noble JC, Cano PO, Lopez PG, Germond CJ., Clinical Cancer Research 2006, 12 (10): 3092-8.

3. Nicolini A, Mancini P, Ferrari P, et al., Biomedicine \& Pharmacotherapy 2004, 58 (8): 447-50.

4. M. Monajjemi, J.E Boggs, J. Phys. Chem A. 2013, 117, 1670.

5. H. Yahyaei\& M. Monajjemi, Fullerenes, Nanotubes, and Carbon Nanostructures, 2014, 22: 346-361.

6. Donelli MG, Bartosek I, Guaitani A, et al., Cancer Treatment Reports 1976, 60(4): 395401.

7. M. Monajjemi, V. S. Lee, M. Khaleghian, B. Honarparvar, F.Mollaamin, J. Phys. Chem C., 2010, 114, 15315.

8. H. Yahyaei, M. Monajjemi, H. Aghaie, and K. Zare, Journal of Computational and Theoretical Nanoscience, 2013, 10(10), 2332-2341.

9. M. Monajjemi, Struct Chem., 2012, 23, 551580.

10. Ramsey-Goldman R, Mientus JM, Kutzer JE,Mulvihill JJ, Medsger TA., The Journal of Rheumatology 1993, 20(7): 1152-7.

11. Majid Monajjemi, Chemical Physics,2013, 425, 29-45.
12. Singh G, Fries JF, Williams CA, Zatarain E, Spitz P, Bloch DA., The Journal of Rheumatology 1991, 18(2): 188-94.

13. M. Monajjemi, F. Naderi, F. Mollaamin, and M. Khaleghian, J. Mex. Chem. Soc. 2012, 56(2), 207-211

14. F. Mollaamin, F. Najafi, M. Khaleghian , B. Khalili Hadad \& M. Monajjemi, Fullerenes, Nanotubes, and Carbon Nanostructures, 2011, 19: 653-667.

15. M. Monajjemi, M. Khaleghian, J Clust Sci., 2011, 22, 673 .

16. Lohrmann HP., Oncology 1984, 41(3): 1804.

17. M. Monajjemi , H. Yamola\& F. Mollaamin, Fullerenes, Nanotubes, and Carbon Nanostructures, 2014, 22: 595-603.

18. F. Mollaamin, M. Monajjemi \& J. Mehrzad, Fullerenes, Nanotubes, and Carbon Nanostructures, 2014, 22: 738-751.

19. M.Monajjemi, S. Afsharnezhad, M.R. Jaafari, T. Abdolahi, A. Nikosade and $\mathrm{H}$. Monajjemi. Russian Journal of physical chemistry $A$, 2007, 2,1956-1963.

20. M. Monajjemi, A. Sobhanmanesh, \& F. Mollaamin, Fullerenes, Nanotubes, and Carbon Nanostructures, 2013, 21: 47-63.

21. Krishna, A. G., D. V. Kumar, et al., Biochimica et Biophysica Acta (BBA) - General Subjects 1998, 1381(1): 104-112. 
22. Glendening, E., J. Badenhoop, et al., "NBO 5.0; Theoretical Chemistry Institute, University of Wisconsin: Madison, WI, 2001, 2004.

23. Reed, A. E., L. A. Curtiss, et al., Chemical Reviews 1988, 88(6): 899-926.

24. M. Monajjemi , N. Karachi \& F. Mollaamin, Fullerenes, Nanotubes, and Carbon Nanostructures, 2014, 22: 643-662.

25. B. Ghalandari, M. Monajjemi, and F. Mollaamin, Journal of Computational and Theoretical Nanoscience, 2011, 8, 12121219.

26. Majid Monajjemi, Robert Wayne, Jrand James E. Boggs, Chemical Physics, 2014 433, 1 -11.

27. T. Ardalan , P. Ardalan\& M. Monajjemi, Fullerenes, Nanotubes, and Carbon Nanostructures, 2014, 22: 687-708.

28. M. Monajjemi, R. Faham\& F. Mollaamin, Fullerenes, Nanotubes, and Carbon Nanostructures, 2012, 20: 163-169.

29. M. Monajjemi ; H. Chegini ; F. Mollaamin ; P. Farahani, Fullerenes, Nanotubes, and Carbon Nanostructures, 2011, 19: 469-482.

30. F. Mollaamin, J. Najafpour, S. Ghadami, A. R. Ilkhani, M. S. Akrami, and M. Monajjemi J. Comput. Theor. Nanosci. 2014, 11: 12901298.

31. M. Monajjemi, M. SeyedHosseini\& F. Molaamin, Fullerenes, Nanotubes, and Carbon Nanostructures, 2013, 21: 381-393

32. M. Monajjemi \& J. Najafpour, Fullerenes, Nanotubes, and Carbon Nanostructures, 2014, 22: 575-594.

33. Kang, M. S., S. H. Kang, et al., Chemical Communications 2012, 48(75): 9349-9351.

34. Frisch, M., G. Trucks, et al. "Gaussian 09, revision B. 01." Gaussian, Inc., Wallingford, CT, 2010.

35. Dadkhah, A., Iranian Rehabilitation Journal 2014, 12(19): 1-10.

36. F. Mollaamina; Z. Varmaghanib; M. Monajjemi, Physics and Chemistry of Liquids, 2011, 49(3), 318-336

37. M. Khaleghian; M. Zahmatkesh; F. Mollaamin; M. Monajjemi, Fullerenes, Nanotubes, and Carbon Nanostructures, 2011, 19: 251-261.

38. Fatemeh Mollaamin \& Majid Monajjemi, Physics and Chemistry of Liquids, 50(5):
2012, 596-604.

39. Glendening, E. D., C. R. Landis, et al., "Natural bond orbital methods." Wiley interdisciplinary reviews: computational molecular science 2012, 2(1): 1-42.

40. M. Monajjemi, and M. Ahmadianarog, Journal of Computational and Theoretical Nanoscience 2014, 11(6), 1465-1471.

41. Boumpas DT, Austin HA, Vaughn EM, et al. Lancet 1992, 340(8822): 741-5.

42. M. Monajjemi, and F. Mollaamin, Journal of Computational and Theoretical Nanoscience, 2012, 9(12), 2208-2214.

43. F. Mollaamin and M. Monajjemi, Journal of Computational and Theoretical Nanoscience , 2012, 9(4), 597-601.

44. Monajjemi, M., E. Rajaeian, et al., Physics and Chemistry of Liquids 2008, 46(3): 299306.

45. Monajjemi, M., H. Chegini, et al., Fullerenes, Nanotubes, and Carbon Nanostructures 2011, 19(5): 469-482.

46. Schreckenbach, G. and T. Ziegler., The Journal of Physical Chemistry 1995, 99(2): 606-611.

47. Bohmann, J. A., F. Weinhold, et al., The Journal of chemical physics 1997, 107(4): 1173-1184.

48. Weinhold, F., Journal of computational chemistry 2012, 33(30): 2440-2449.

49. Schreckenbach, G. and T. Ziegler., The Journal of Physical Chemistry A 1997, 101(18): 3388-3399.

50. Chen, Z., C. S. Wannere, et al., Chemical reviews 2005, 105(10): 3842-3888.

51. Kaupp, M., M. Bühl, et al., Calculation of NMR and EPR parameters: theory and applications, John Wiley \& Sons, 2006.

52. Becke, A. D., A. A. Arabi, et al., Canadian Journal of Chemistry 2010, 88(11): 10571062.

53. M Arivazhagan\& J SenthilKumar,,Indian Journal of Pure \& Applied Physics 2012, 50, 363-373.

54. Bonness, S., H. Fukui, et al., Chemical Physics Letters 2010, 493(1): 195-199.

55. Zeng, X.-L., X.-L. Zhang, et al. Chemosphere 2013, 91(2): 229-232.

56. Glendening, E. D., C. R. Landis, et al., "Natural bond orbital methods." Wiley interdisciplinary 
reviews: computational molecular science 2012, 2(1): 1-42.

57. Weinhold, F. and R. A. Klein., "What is a hydrogen bond? Mutually consistent theoretical and experimental criteria for characterizing $\mathrm{H}$-bonding interactions."
Molecular Physics 2012, 110(9-10): 565-579.

58. Huttunen KM, Raunio H, Rautio J "Prodrugs-from serendipity to rational design". Pharmacological Reviews 2011, 63(3): 750-71. 